\title{
Stimulation of Spermiation by Human Chorionic Gonadotropin and Carp Pituitary Extract in Grass Puffer, Takifugu niphobles
}

\author{
${ }^{\dagger}$ In Bon Goo ${ }^{1}$, In-Seok Park ${ }^{2}$, Hyun Woo Gil ${ }^{2}$ and Jae Hyun Im $^{1}$ \\ ${ }^{1}$ Inland Aquaculture Research Center, National Fisheries Research \& Development Institute, Changwon 645-806, Korea \\ ${ }^{2}$ Division of Marine Bioscience, College of Ocean Science and Technology, \\ Korea Maritime and Ocean University, Busan 606-791, Korea
}

\begin{abstract}
Spermiation was stimulated in the mature grass puffer, Takifugu niphobles, with an injection of human chorionic gonadotropin (HCG) or carp pituitary extract (CPE). Spermatocrit and sperm density were reduced, but milt production was increased in both the HCG and CPE treatment groups relative to those in the control group $(P<0.05)$. These results should be useful for increasing the fertilization efficiency in grass puffer breeding programs.
\end{abstract}

Key words : Milt production, Spermatocrit, Sperm density

\section{INTRODUCTION}

Injections or implantation of gonadotropin-releasing hormone, gonadotropin, or steroid hormones are used to control and facilitate spermatogenesis and spermiation in fish, and these treatments are easier and simpler to administer to the testes than to the ovaries. Human chorionic gonadotropin (HCG) is a hormone that effectively stimulates spermiation in fish, and HCG at 100-10,000 IU/kg bodyweight (BW) has shown concentration-dependent effects on spermiation in the goldfish, Carassius auratus, the rainbow trout, Oncorhynchus mykiss, the seabream, Sparus aurata, the milkfish, Chanos chanos, the European eel Anguilla anguilla, and the Japanese eel, A. japonica (Donaldson \& Hunter, 1983; Park et al., 1992). Carp pituitary extract (CPE) is widely used to induce spawning, but it has the disadvantage of varying in potency according to the sex, age, and maturity of the donor, the time of donation, and the species specificity of the donor/recipient (Lam, 1982). The regulatory effects of these hormones on spermiation in fish are difficult to assess, and have only been evaluated qualitatively in salmonids, was attendance on spermatocrit the measurement of sperm conjunction with concentration and volume (Shehadeh et al., 1973; Juario et al., 1980; Munkittrick \& Moccia, 1987).

The grass puffer, Takifugu niphobles (Tetraodontiformes, Tetraodontidae), is found throughout Korea, Japan, and Southeast Asia, usually along rocky seashores (Han \& Kim, 1998). It is valued as an experimental animal and is occasionally used as a model species for other Takifugu (Hamasaki et al., 2013). Grass puffer males mature as early as 10 months of age, and can be reared in small

\footnotetext{
Manuscript received November 10, 2015, Received in revised form November 19, 2015, Accepted December 1, 2015

${ }^{\dagger}$ Corresponding Author: In Bon Goo, Inland Aquaculture Research Center, National Fisheries Research \& Development Institute, Changwon 645-806, Korea. Tel. : +82-55-540-2706, Fax : +82-55-540-6292, E-mail : bourne@kmou.ac.kr

This is an Open Access article distributed under the terms of the Creative Commons Attribution Non-Commercial License (http:// creativecommons.org/licenses/by-nc/3.0) which permits unrestricted non-commercial use, distribution, and reproduction in any medium, provided the original work is properly cited.
} 
spaces because their size at maturity is only $13 \mathrm{~g}$ (Hamasaki et al., 2013). Grass puffer is a commercially important food fish in Korea, and is considered to be a good candidate for mariculture because of its market potential and its suitability for production with commercial seafarming methods. However, few studies have specifically targeted the grass puffer, and no research has been undertaken into the spermiation of this species.

Therefore, as part of a larger study of grass puffer breeding, the effects of HCG and CPE injections on spermiation in the mature grass puffer were investigated by measuring sperm production, sperm concentration, and spermatocrit.

\section{MATERIALS AND METHODS}

Male grass puffers (mean standard length \pm SD: $13.4 \pm$ $1.4 \mathrm{~cm}$; mean body weight \pm SD: $27 \pm 8.3 \mathrm{~g}$ ) were used in this experiment. The specimens were collected for one month in June 2013, the spawning season, by fishing along the Korean coast and the fish were reared in the Fishery Genetics and Breeding Science Laboratory at the Korea Maritime and Ocean University, Busan, in circular tanks (Ф $1.5 \mathrm{~m}$ ). Each tank contained 200 fish, with three replicate samples of each group.

The experimental groups were supplied with sufficient food twice a day. The ammonia level was less than 0.001 ppm, the nitrous acid concentration was $0.08-0.1 \mathrm{ppm}$, the nitric acid concentration was $2-5 \mathrm{ppm}$, the $\mathrm{pH}$ was $8.2-8.5$, the water temperature was $21 \pm 1{ }^{\circ} \mathrm{C}$, and the specific gravity was 1.025 . The body length and $\mathrm{BW}$ of the fish were measured after they were anaesthetized with lidocaine$\mathrm{HCl}$ (300 ppm hydrochloric lidocaine/1,000 ppm $\mathrm{NaHCO}_{3}$ ) at $22^{\circ} \mathrm{C}$, according to Park et al. (1988). Smooth pressure was applied by hand to release the sperm (Fig. 1), which was collected with $1 \mathrm{~mL}$ disposable syringes and used for the analysis.

To determine the centrifugation conditions with which

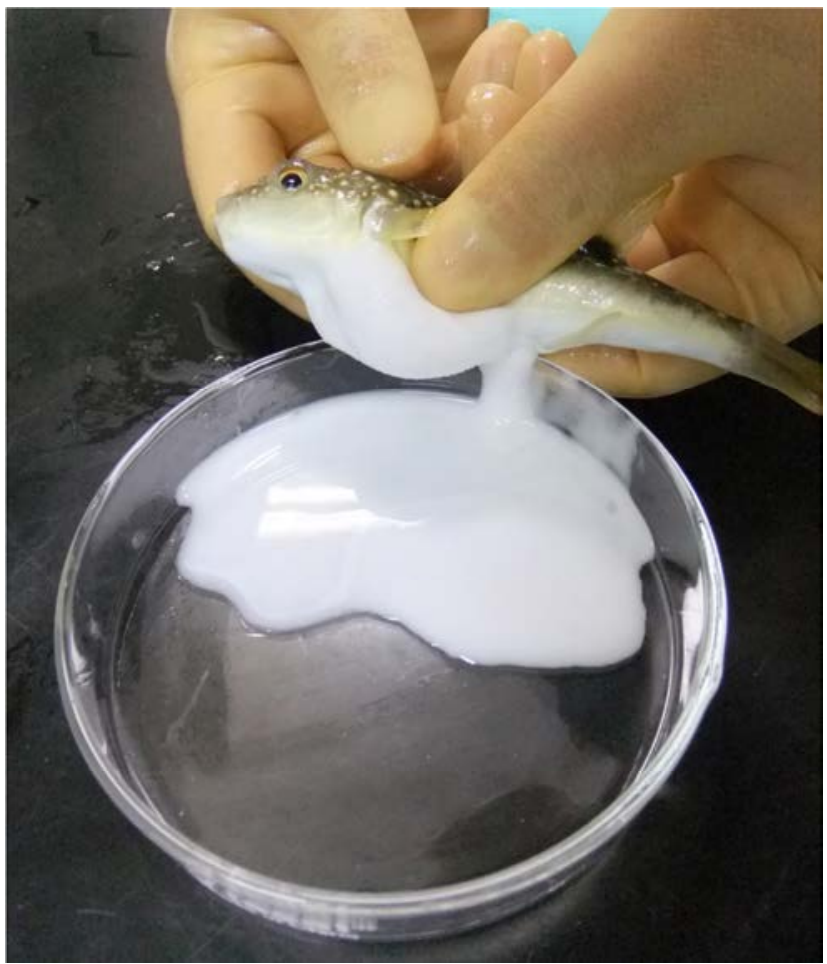

Fig. 1. Milt collection by hand stripping from the grass puffer, Takifugu niphobles. The fish were anaesthetized with with lidocaine- $\mathrm{HCl}$ (300 ppm hydrochloric lidocaine/1,000 ppm $\mathrm{NaHCO}_{3}$ ) and then each grass puffer was gripped on its dorsal side. The urogenital area was wiped clean and dried with absorbent paper. Urine and some faeces were initially forced out by gentle massage of the abdomen.

to concentrate the spermatozoa for the calculation of the stable spermatocrit, the semen collected from 10 mature male fish was collected into non-heparinized microhaematocrit capillary tubes (i.d. 1.1-2.0 mm $\times 75 \mathrm{~mm}$; Fisher Scientific, USA), which were sealed with sealing compound (Fisher Scientific) and centrifuged for 5, 10, 15, 20, 25, 30, 40, 60, $70,80,100$ or $120 \mathrm{~min}$ at $12,000 \mathrm{rpm}$ in a microhaematocrit centrifuge (Hettich, Japan). Sperm were collected from 1,200 grass puffer males for two weeks in the spawning season. The sperm were diluted with $0.9 \% \mathrm{NaCl}$ and the spermatozoa counted with a haemocytometer counting chamber under a microscope (Carl Zeiss, Germany) at $400 \times$ magnification. The sperm density was calculated as 
the number of spermatozoa per microlitre of milt, and the relationship between sperm density and spermatocrit was represented by a quadratic function.

To analyze the effects of HCG and CPE on spermiation, one or other hormone was injected into the abdominal cavity of each fish. Spermatocrit, sperm density, and milt production were measured in the control and treatment groups and compared immediately after injection, 24 hours after injection, and 48 hours after injection. Grass puffer males $(n=400)$ randomly caught in the tanks were used in the experiment. For the HCG treatment, HCG (Sigma, USA) was diluted to concentrations of 500, 1,000 and 2,000 IU/kg BW and administered to the appropriate treatment groups $(n=50)$. For the CPE treatment, CPE (Stoler Fisheries USA, USA) was diluted to concentrations of 50,100 and $200 \mathrm{mg} / \mathrm{kg} \mathrm{BW}$, which were injected into the appropriate treatment groups $(n=50)$. The control group ( $n=50)$ was injected with saline solution only, using a $1 \mathrm{~mL}$ disposable syringe. Each experimental group was housed separately and there were three replicate samples for each group.

The spermatocrit and sperm density of the sperm collected immediately after injection, 24 hours after injection, and 48 hours after injection were measured as described above. Milt production was measured as the volume of sperm collected per $\mathrm{kg} \mathrm{BW}$. The data were analyzed using oneand two-way analysis of variance (ANOVA) to determine whether the values for each set of experimental data were significantly different.

\section{RESULTS AND DISSCUSSION}

The grass puffer sperm started precipitate after $20 \mathrm{~min}$ at $12,000 \mathrm{rpm}$, and this separation decreased gradually after $40 \mathrm{~min}$. In the final outcome, spermatocrit was stable after centrifugation for 40, 50, 60, 70, 80, 100 and $120 \mathrm{~min}$ (Fig. 2 ). Based on the range of centrifugation times required to establish a stable spermatocrit, $60 \mathrm{~min}$ at 12,000 rpm was

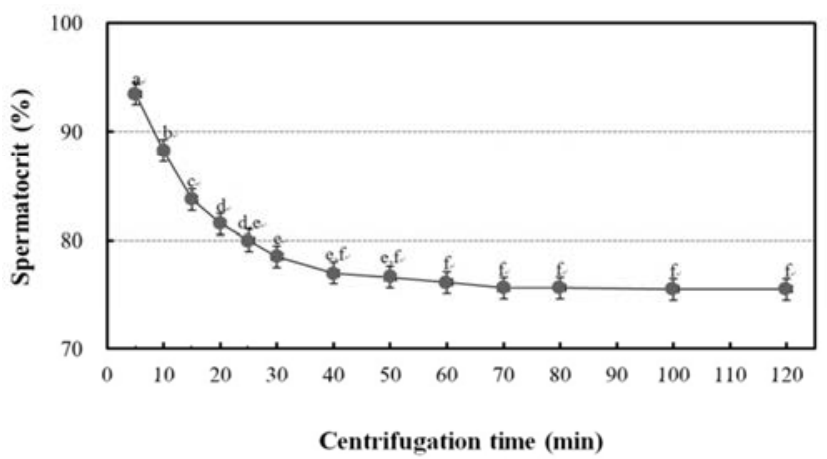

Fig. 2. The effect of centrifugation time on the spermatocrit of the grass puffer, Takifugu niphobles. Milt in non-heparinized microhaematocrit capillary tubes was centrifuged at 12,000 rpm. Points identified with the same letter are not significantly different according to Duncan's multiple range test $(P>$ $0.05)$. Each point represents the mean $\pm \mathrm{SD}(n=10)$ of triplicate tubes.

selected as the suitable conditions for spermatocrit measurement. The relationship between sperm density and spermatocrit was $\mathrm{Y}=6.441 \mathrm{X}+20.44$ ( $\mathrm{Y}$ is spermatocrit, $\mathrm{X}$ is sperm density, $\mathrm{R}^{2}=0.842, n=1,200$; Fig. 3 ).

The effects of HCG on spermatocrit, sperm density, and milt production depended on the time and dose given, as

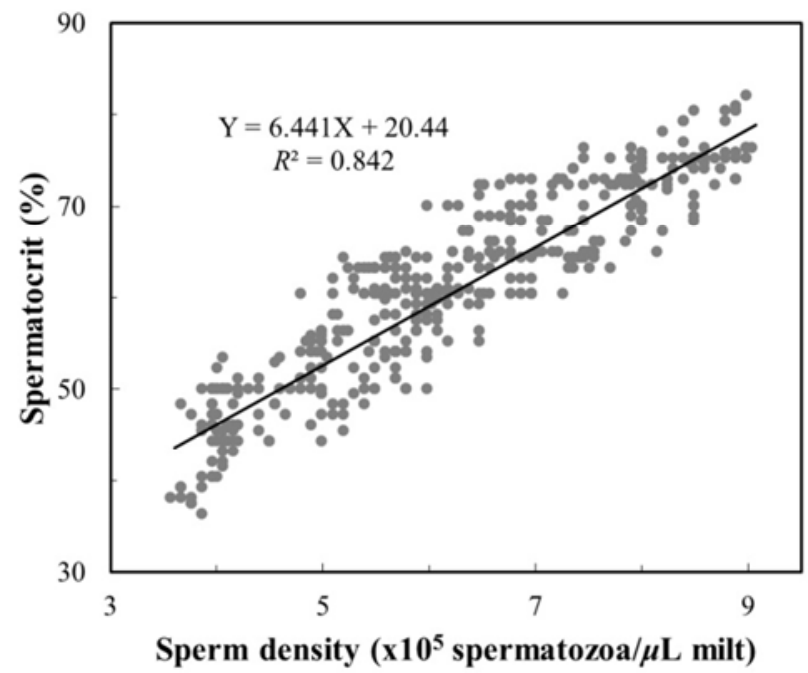

Fig. 3. The relationship between sperm density and spermatocrit in the grass puffer, Takifugu niphobles. $\mathrm{Y}$ is spermatocrit $(\%), \mathrm{X}$ is sperm density $\left(\times 10^{5}\right.$ spermatozoa/ $\mu \mathrm{L}$ milt). 
Table 1. Changes in spermatocrit, sperm density, and milt production in the mature grass puffer, Takifugu niphobles, after an injection of human chorionic gonadotropin (HCG)*

\begin{tabular}{ccccc}
\hline \hline $\begin{array}{c}\text { Exp. group } \\
\text { (IU/kg BW) }\end{array}$ & $\begin{array}{c}\text { Hours after } \\
\text { injection }\end{array}$ & $\begin{array}{c}\text { Spermatocrit } \\
(\%)\end{array}$ & $\begin{array}{c}\text { Sperm density } \\
\left(\times 10^{5} \text { spz/ } / \mu \text { milt }\right)\end{array}$ & $\begin{array}{c}\text { Milt production } \\
(\mathrm{mL} / \mathrm{kg} \mathrm{BW})\end{array}$ \\
\hline Cont. & & $75.0 \pm 0.79^{\mathrm{Aa}}$ & $8.0 \pm 0.85^{\mathrm{Aa}}$ & $57.8 \pm 17.19^{\mathrm{Aa}}$ \\
500 & & $75.2 \pm 0.57^{\mathrm{Aa}}$ & $7.9 \pm 1.24^{\mathrm{Aa}}$ & $53.4 \pm 13.24^{\mathrm{Ab}}$ \\
1,000 & 0 & $75.6 \pm 0.96^{\mathrm{Aa}}$ & $7.8 \pm 1.39^{\mathrm{Aa}}$ & $52.9 \pm 14.29^{\mathrm{Bb}}$ \\
2,000 & $75.1 \pm 0.74^{\mathrm{Aa}}$ & $8.1 \pm 1.13^{\mathrm{Aa}}$ & $55.6 \pm 15.34^{\mathrm{Ab}}$ \\
\hline Cont. & & $72.0 \pm 9.85^{\mathrm{Aa}}$ & $6.5 \pm 0.30^{\mathrm{Ab}}$ & $57.6 \pm 12.94^{\mathrm{Ca}}$ \\
500 & & $65.0 \pm 14.11^{\mathrm{Bb}}$ & $7.5 \pm 1.19^{\mathrm{Ba}}$ & $22.4 \pm 33.81^{\mathrm{Dc}}$ \\
1,000 & $50.3 \pm 5.03^{\mathrm{Cb}}$ & $7.2 \pm 0.92^{\mathrm{Bb}}$ & $109.4 \pm 34.76^{\mathrm{Aa}}$ \\
2,000 & 24 & $44.0 \pm 6.93^{\mathrm{Db}}$ & $5.4 \pm 0.71^{\mathrm{Cb}}$ & $96.0 \pm 15.24^{\mathrm{Ba}}$ \\
\hline Cont. & & $64.7 \pm 11.93^{\mathrm{Ab}}$ & $6.7 \pm 0.67^{\mathrm{Ab}}$ & $17.1 \pm 9.53^{\mathrm{Cb}}$ \\
500 & & $61.0 \pm 5.57^{\mathrm{Ab}}$ & $6.6 \pm 2.45^{\mathrm{Bb}}$ & $58.3 \pm 27.07^{\mathrm{Aa}}$ \\
1,000 & & $54.7 \pm 7.02^{\mathrm{Bb}}$ & $6.6 \pm 2.82^{\mathrm{Bc}}$ & $41.8 \pm 9.32^{\mathrm{Bc}}$ \\
2,000 & 48 & $40.7 \pm 7.23^{\mathrm{Cb}}$ & $5.4 \pm 1.69^{\mathrm{Cb}}$ & $42.1 \pm 4.62^{\mathrm{Bc}}$
\end{tabular}

*Means \pm SD $(n=50)$ of triplicate groups. Data were analyzed using one- and two-way ANOVA. Different capital letters on the values indicate statistically significant differences among doses at each time after injection $(P<0.05)$. Different small letters on the values indicate statistically significant differences among times after injection for each dose $(P<0.05)$. Cont.: control group; Exp.: experimental group; spz.: spermatozoa.

shown in Table 1. The HCG treatment groups showed reductions in spermatocrit and sperm density, but increases in milt production relative to the control group $(P<0.05)$. Table 2 shows the effects of CPE on spermatocrit, sperm density, and milt production according to time and dose. The effects of CPE were similar to those of HCG, reducing spermatocrit and sperm density, but increasing milt production relative to those of the control group $(P<0.05)$. Fig. 4 shows the external morphology of the spermatozoa 48 hours after the hormone injection. The sperm densities of the HCG and CPE treatment groups (Tables 1 and 2, Fig. $4 \mathrm{~B}$ and $4 \mathrm{C}$ ) were clearly lower than that of the control group (Fig. 4A).

The spermatocrit method has been used to confirm the effects of hormones on spermiation in salmonids and the olive flounder, Paralichthys olivaceus. There is an intimate relationship between sperm density and spermatocrit, so

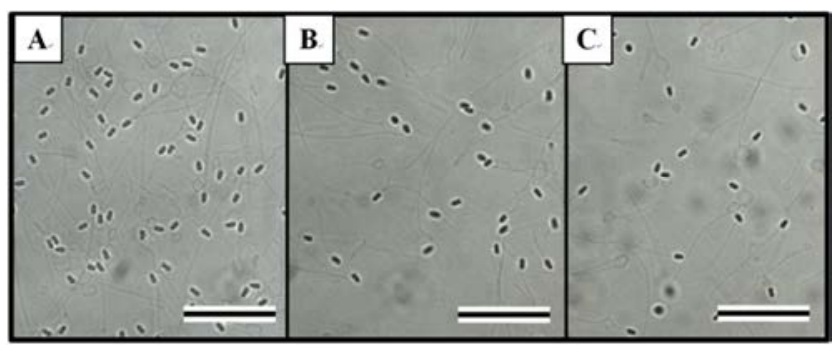

Fig. 4. External morphology of the grass puffer, Takifugu niphobles spermatozoa 48 hours after hormone injection. (A) Control, (B) 2,000 IU HCG/kg BW, and (C) $20 \mathrm{mg} \mathrm{CPE} / \mathrm{kg} \mathrm{BW}$. Each sperm sample was diluted with $0.9 \% \mathrm{NaCl}$. Bars are $20 \mu \mathrm{m}$.

the method used in this experiment was more suitable for confirming the effects of the hormones on spermiation (Munkittrick \& Moccia, 1987; Garcia, 1991; Park et al., 1992). In our experiment, the conditions used to establish a stable spermatocrit in the grass puffer, with centrifugation at $12,000 \mathrm{rpm}$ for $60 \mathrm{~min}$, may also be applicable to other 
Table 2. Changes in spermatocrit, sperm density, and milt production in the mature grass puffer, Takifugu niphobles, after an injection of carp pituitary extract (CPE)*

\begin{tabular}{ccccc}
\hline $\begin{array}{c}\text { Exp. group } \\
(\mathrm{mg} / \mathrm{kg} \mathrm{BW})\end{array}$ & $\begin{array}{c}\text { Hours after } \\
\text { injection }\end{array}$ & $\begin{array}{c}\text { Spermatocrit } \\
(\%)\end{array}$ & $\begin{array}{c}\text { Sperm density } \\
\left(\times 10^{5} \text { spz/ } \mu \text { L milt }\right)\end{array}$ & $\begin{array}{c}\text { Milt production } \\
(\mathrm{mL} / \mathrm{kg} \mathrm{BW})\end{array}$ \\
\hline Cont. & & $75.0 \pm 0.79^{\mathrm{Aa}}$ & $8.0 \pm 0.84^{\mathrm{Aa}}$ & $57.8 \pm 17.19^{\mathrm{Aa}}$ \\
5 & & $75.2 \pm 0.84^{\mathrm{Aa}}$ & $7.9 \pm 0.93^{\mathrm{Aa}}$ & $55.7 \pm 13.75^{\mathrm{Ab}}$ \\
10 & 0 & $75.0 \pm 0.71^{\mathrm{Aa}}$ & $8.3 \pm 1.31^{\mathrm{Aa}}$ & $58.1 \pm 11.32^{\mathrm{Ab}}$ \\
20 & & $74.8 \pm 0.84^{\mathrm{Aa}}$ & $7.8 \pm 0.98^{\mathrm{Aa}}$ & $56.9 \pm 12.85^{\mathrm{Ab}}$ \\
\hline Cont. & & $72.0 \pm 9.85^{\mathrm{Aa}}$ & $6.5 \pm 0.30^{\mathrm{Ab}}$ & $57.6 \pm 12.94^{\mathrm{Ca}}$ \\
5 & 24 & $60.7 \pm 26.5^{\mathrm{Bb}}$ & $4.8 \pm 0.71^{\mathrm{Bb}}$ & $79.0 \pm 42.40^{\mathrm{Ba}}$ \\
10 & $63.7 \pm 7.02^{\mathrm{Bb}}$ & $4.7 \pm 0.93^{\mathrm{Bb}}$ & $83.8 \pm 27.25^{\mathrm{Ba}}$ \\
20 & & $64.7 \pm 9.24^{\mathrm{Bb}}$ & $4.1 \pm 1.12^{\mathrm{Cb}}$ & $89.4 \pm 72.18^{\mathrm{Aa}}$ \\
\hline Cont. & & $64.7 \pm 11.93^{\mathrm{Ab}}$ & $6.7 \pm 0.67^{\mathrm{Ab}}$ & $17.1 \pm 9.53^{\mathrm{Bb}}$ \\
5 & & $55.3 \pm 21.96^{\mathrm{Bc}}$ & $4.8 \pm 2.63^{\mathrm{Bb}}$ & $32.8 \pm 30.34^{\mathrm{Ac}}$ \\
10 & $61.3 \pm 11.73^{\mathrm{Ab}}$ & $4.6 \pm 2.15^{\mathrm{Bb}}$ & $37.9 \pm 45.93^{\mathrm{Ac}}$ \\
20 & 48 & $51.3 \pm 19.35^{\mathrm{Bc}}$ & $4.1 \pm 2.51^{\mathrm{Cb}}$ & $13.2 \pm 9.34^{\mathrm{Bc}}$ \\
\hline
\end{tabular}

*Means \pm SD $(n=50)$ of triplicate groups. Data were analyzed using one- and two-way ANOVA. Different capital letters on the values indicate statistically significant differences among doses at each time after injection $(P<0.05)$. Different small letters on the values indicate statistically significant differences among times after injection for each dose $(P<0.05)$. Cont.: control group; Exp.: experimental group; spz.: spermatozoa.

marine fish species.

The sperm density of the mature grass puffer was slightly higher than those of salmonids, the rabbitfish, and the olive flounder (Scott \& Bayness, 1980; Garcia, 1991). HCG and CPE exerted synergistic effects on the spermiation of the grass puffer, as has already been shown in a previous study of the goldfish, rainbow trout, seabream, milkfish, European eel, and olive flounder (Park et al., 1992). The reduction in the sperm concentration after the hormone injection may be attributable to the hydration of the testis by the mature hormone (Clemens \& Grant, 1965; Billard et al., 1982; Avila, 1984; Garcia, 1991; Park et al. 1992). This would explain the reductions in spermatocrit and sperm density, and the increased milt production observed in this experiment relative to those in the control group. HCG and CPE are used to stimulate spermiation because highly concentrated sperm is difficult to dilute (Shehadeh et al., 1973; Juario et al., 1980).

The stimulatory effects of HCG and CPE on spermiation assessed in this study should be usefully applied to increase fertilization efficiency later in grass puffer seed production. However, the survival of spermatozoa after HCG and CPE treatments, administered at various concentrations and at different times, must be investigated in a future study to determine the minimum active concentration and the optimal time of administration. However, it has previously been shown that sperm hydration induced by the administration of hormone improved fertility by 98 $100 \%$, but entailed a low hatch rate (Garcia, 1991). For these reasons, an analysis of the fertility rates, hatching rates, early survival rates, and abnormality rates in this species after sperm hydration is required. 


\section{ACKNOWLEDGMENTS}

This work was supported by a grant from the National Fisheries Research and Development Institute (R2015002), Korea.

\section{REFERENCES}

Avila EM (1984) Hormone-induced spawning and embryonic development of the rabbitfish, Siganus vermiculatus (Pisces: Siganidae). Philipp Sci 21:75-108.

Billard R, Fostier A, Weil C, Breton B (1982) Endocrine control of spermatogenesis in teleost fish. Can J Fish Aquat Sci 39:65-79.

Clemens HP, Grant FB (1965) The seminal thinning response of carp (Cyprinus carpio) and rainbow trout (Salmo gairdneri) after injections of pituitary extracts. Copeia 2:174-177.

Donaldson EM, Hunter GA (1983) Induced final maturation, ovulation, and spermiation in cultured fish. In: Hoar WE, Randall DJ, Donaldson EM (eds.), Fish Physiology Vol. IXB. Academic Press, New York. pp 51403.

Garcia LMB (1991) Spermiation response of mature rabbitfish, Siganus guttatus Bloch, to luteinizing hormonereleasing hormone analogue (LHRHa) injection. Aqua culture 97:291-299.

Hamasaki M, Takeuchi Y, Miyaki K, Yoshizaki G (2013) Gonadal development and fertility of triploid grass puffer, Takifugu niphobles induced by cold shock treatment. Mar Biotechnol 15:133-144.
Han KH, Kim YU (1998) Generic characters of the fishes of the family Tetraodontidae (Teleostei: Tetraodontiformes). J Kor Fish Soc 31:309-316.

Juario JV, Quinitio GF, Banno JE, Natividad M (1980) Effects of exogenous hormone injection on milt consistency in newly caught, wild milkfish. Kalikasan: Philipp J Biol 9:321-326.

Lam TJ (1982) Application of endocrinology to fish culture. Can J Fish Aquat Sci 39:111-137.

Munkittrick KR, Moccia RD (1987) Seasonal changes in the quality of rainbow trout (Salmo gairdneri) semen: effect of a delay in stripping on spermatocrit, motility, volume and seminal plasma constituents. Aquaculture 64:147-156.

Park I-S, Kim H-B, Choi H-J, Lee Y-D, Son JK (1992) Stimulation of spermiation by human chorionic gonadotropin (HCG) in mature flatfish, Paralichthys olivaceus. Bull Mar Res Inst 16:75-82.

Park I-S, Kim JM, Kim YH, Kim DS (1988) Influence of lidocaine as an anaesthetic for marine fishes. J Fish Pathol 1:123-130.

Scott AP, Baynes SM (1980) A review of the biology, handling and storage of salmonid spermatozoa. J Fish Biol 17:707-739.

Shehadeh ZH, Madden WD, Dohl TP (1973). The effect of exogenous hormone treatment on spermiation and vitellogenesis in the grey mullet, Mugil cephalus L. J Fish Biol 5:497-487. 